\title{
Association of Leptin Receptor Q223R Gene Polymorphism and Breast Cancer Patients: A Case Control Study
}

\author{
Manar F Atoum ${ }^{1 *}$, Ala'a Abdel Hamaid Alparrey²
}

\begin{abstract}
Introduction: Leptin is a hormone secreted from adipocytes that regulates metabolism and energy homeostasis through the leptin receptor (LEPR). The aim of this study was to investigate the association of leptin receptor gene Q223R gene polymorphism, and plasma leptin level among obese breast cancer females. Materials and Methods: The study enrolled 160 breast cancer patients and 160 healthy control females. LEPR Q223R polymorphism was determined by polymerase chain reaction-restriction fragment length polymorphism (PCR-RFLP). Serum leptin was determined using enzyme-linked immunosorbent assay human leptin kit. Immunohistochemical tests from paraffin blocks were carried out for estrogen and progesterone staging using the precise antibodies. Results: An association was found between LEPR gene Q223R gene polymorphism among obese breast cancer females. Statistical difference was found between $\mathrm{GG}(60.6 \%) \mathrm{Arg} / \mathrm{Arg}$ genotype $(\mathrm{OR}=2.986 ; 95 \% \mathrm{CI}=1.540$ to $5.789 ; \mathrm{p}=0.001)$ compared to AA $(33.1 \%) \mathrm{Gln} /$ Gln genotype. GG Q223R LEPR polymorphism showed statistically significant difference among obese breast cancer patients (BMI more than 25) compared to control $(\mathrm{P}<0.0001)$. GG genotype of Q223R LEPR polymorphism showed statistically significant increased leptin level ( $p$-value $=0.0001$ ) among obese patients (mean $\pm \mathrm{SD} ; 23.39 \pm 4.32$ ) compared to control (17.83 \pm 5.67$)$. Conclusions: Q223R LEPR polymorphism GG genotype was associated with increased leptin profile among obese breast cancer females.
\end{abstract}

Keywords: LEPR gene Q223R- breast cancer- body mass index- leptin receptor- PCR-RFLP- polymorphism

Asian Pac J Cancer Prev, 23 (1), 177-182

\section{Introduction}

Obesity is a complex process that arise from complex relationships between genes, socioeconomic, cultural influences, lifestyle and environmental factors. It is a condition of having excess body fat and defined as having a body mass index (BMI) dividing the weight of an individual by the square of their height of $\geq 30$, whereas BMIs from 18.5 to 24.9 are normal while BMIs $\geq 25$ to $<30$ are considered overweight (Chooi et al., 2019). Elevated BMI and weight gain have been associated with increased postmenopausal breast cancer risk among ER-positive and PR-positive breast cancer (Kabat et al., 2017). Studies showed that for every 5 -unit increase in BMI above 25 $\mathrm{kg} / \mathrm{m} 2$, mortality increases by $29 \%$, vascular mortality by $41 \%$, and diabetes-related mortality by $210 \%$ (Whitlock et al., 2009).

The four mechanisms that link breast cancer with obesity include: leptin and leptin receptor expression, adipose chronic inflammation, sex hormone alternation, and insulin and insulin like growth factor 1 (IGF-1) signaling (Atoum et al., 2017; Atoum et al., 2020). These mechanisms lead to an increase in the adipokine leptin that stimulate low-grade chronic inflammation that affects white adipose tissue, which motivate an energy imbalance and signaling pathways activation that express the inflammatory mediators and cytokines (Gregor et al., 2011; Ellulu et al., 2017). Leptin plays a role in the epithelial-mesenchymal transition that leads to cancer cell migration and metastasis. Leptin plays a role on insulin-like growth factor-I, epidermal growth factor receptor and HER2/neu (Amitabha et al., 2017). Leptin has been connected to breast cancer initiation, development, and progression through signaling transduction network (Ehmsen et al., 2020). Elevated blood leptin concentrations or increased leptin receptors expression are associated with poor prognosis, lymph node involvement and cancer metastasis (Tsung-Chieh et al., 2021).

Leptin performances its action by binding to its membrane receptor. Six LEPR isoforms were identified by the cloning strategy. All LEPR isoforms have the same extracellular ligand-binding domain at the $\mathrm{N}$-terminus, but they differ in the intracellular domain and their physiological roles (Angela et al., 2017). Leptin receptor is a transmembrane protein that fits into a cytokine receptors superfamily and has six isoforms. The long isoform mainly located in the hypothalamus and the other short isoforms located different tissues (Pérez-Montarelo et al., 
2013). Leptin receptors dimers are capable of stimulating transcription by activating Janus kinases (Zabeau et al., 2014). A systematic meta-analysis (Gholamalizadehet al., 2019) showed that fat mass and obesity-related (FTO) is the most scientifically plausible cause that connect obesity with cancer. The association between FTO, obesity and cancer has been confirmed through the presence of single-nucleotide polymorphisms (SNPs). Many FTO gene SNPs including rs9939609, rs17817449, rs8050136, rs1477196, rs6499640, rs16953002, rs11075995, and rs1121980 (Hernández-Caballero et al., 2015) showed their etiologic role in incidence of breast cancer. LEPR Q223R polymorphism disturb leptin binding to its receptor and result in A to G substitution at exon 6, nucleotide 668 and codon 223 of the initiation codon. The aim of this study is to determine the association between the LEPR rs1137101 (Gln223Arg) SNP, leptin level and obesity among Jordanian breast cancer females.

\section{Materials and Methods}

One hundred and sixty breast cancer females and 160 healthy control females were enrolled in this study. This report fits Helsinki Declaration, and ethical approval was gained from the Hashemite University Institutional Review Board. Consent forms were signed by all participants (patients and control) before interviewing and sample collection. Samples were collected from breast clinic at Al-Basheer Hospital, Amman, Jordan (2018) by a specialized pathologist. Breast cancer were TNM staged according to the National Cancer Institute-National Institute of Health and revised by the American Joint Committee on Cancer Staging System for Breast Cancer (Singletary et al., 2002). Blood samples (5ml EDTA and $5 \mathrm{ml}$ plain tube) were collected for leptin detection and PCR-RFLP genotyping.

By using the standardized procedures, anthropometric measurements were verified. Height was read to the nearest $0.5 \mathrm{~cm}$. Weight was determined by digital scale. Body mass index (BMI) was calculated as person's weight in kilograms divided by the square of height in meters.

Leptin level were measured using enzyme-linked immunosorbent assay (ELISA) kit (EIA-2395; DRG Inc., USA). ELISA was carried out by a solid-phase sandwich ELISA with an affinity-purified polyvalent antibody immobilized in microtiter wells. Bound leptin was detected with affinity-purified antibody conjugated to horseradish peroxidase and quantified by a chromogenic substrate.

Immunohistochemical tests from appropriate paraffin blocks were carried out for estrogen and progesterone staging using suitable antibodies. Sections were made $(5 \mu \mathrm{m})$, put on slides and deparaffinized steps were done using a xylene bath and rehydration step using descending ethanol concentrations baths $95 \%, 90 \%$, and $75 \%$, then followed by a distilling water bath for 5 minutes. Incubation with the primary antibody has performed after washing with PBS solution for 5 minutes, and incubation step at $37^{\circ} \mathrm{C}$ for one hour. Primary antibodies used were ER (monoclonal mouse anti-human estrogen receptor $\alpha$; DAKO Cytomation, Denmark) and PR (monoclonal mouse anti-human progesterone receptor; DAKO Cytomation, Denmark). The tissues were then washed with PBS/ Tween and then incubated with HPR detection system for 30 minutes at room temperature. Signal visualization was carried out using diaminobenzidine DAB. Hematoxylin was then used for nuclei counterstaining.

DNA was extracted for genotyping using the QIAamp DNA Mini Kit (QIAgen Inc., USA) and according to the manufactural instructions. DNA yield was $5.5 \mu \mathrm{g}$ and A260/A280 ratio was 1.68-1.92. Genotypes were determined by PCR-RFLP. Primers sequences were used to amplify Q223R polymorphisms with sequences for forward: 5-ACCCTTTAAGCTGGGTGTCCCAAATAG-3 and for backward: 5-AGCTAGCAAATATTTTGTAAGCAATT-3 .PCR cocktail was as follows: $2.5 \mu \mathrm{L}$ PCR buffer, $1 \mu \mathrm{L}$, $0.5 \mu \mathrm{L}$ dNTP mix, $1 \mu \mathrm{L}$ of each primer, $3 \mu \mathrm{L}$ template DNA, and $0.3 \mu \mathrm{L}$ Taq DNA Polymerase (Go TaqDNA Polymerase; Invitrogen).

PCR program for polymorphism determination was as follows: initial denaturation at $94^{\circ} \mathrm{C}$ for 4 minutes; 40 cycles including denaturation at $94^{\circ} \mathrm{C}$ for $30 \mathrm{~s}$, annealing at $58^{\circ} \mathrm{C}$ for $30 \mathrm{~s}$, and extension at $72^{\circ} \mathrm{C}$ for $30 \mathrm{~s}$; and final extension at $72^{\circ} \mathrm{C}$ for $10 \mathrm{~min}$. To confirm amplification of the desired fragments, all samples were electrophoresed on $1.5 \%$ agarose gel after PCR. Samples were then digested with MspI enzyme (New England Biolabs) for leptin receptor gene for $16 \mathrm{~h}$. The products then electrophoresed on 2\% agarose gel. Q223R LEPR polymorphism were detected by the appearance of $416 \mathrm{bp}$ band for GG homozygous genotype, three bands of 416bp, $291 \mathrm{bp}$, and $125 \mathrm{bp}$ length for AG heterozygous genotype, and two bands of 125bp and 291bp for AA homozygous genotype.

Genotypes were categorized for both breast cancer females and control according to gel electrophoresis bands that were digested with MspI enzyme. All samples are within Hardy Weinberg equilibrium (Table 2). Chi-squared test was used to compare the differences between different Q223R LEPR polymorphisms among breast cancer and control. The relationship between case and control were evaluated using odd ratio (OR) and 95\% confidence interval (CI) were calculated. Comparison of mean leptin levels among obese and non-obese breast cancer patients with Q223R LEPR polymorphism was carried out by unpaired t test. Statistical analysis was carried out sing the Statistical Package for Social Sciences (SPSS) version 8.0 (SPSS Inc, Chicago, IL). P-value $<0.05$ is considered as statistically significant.

\section{Results}

The mean age of breast cancer patients and control was $58.51= \pm 7.1$ and $55.3= \pm 5.3$; respectively (Table 1). This study showed a significant statistical difference in BMI between breast cancer females $(29.51 \pm 4.7)$ compared to $(22.98 \pm 3.8)$ among control p-value $<.0001$ (Table 1)

All genotypes are within Hardy Weinberg equation Chi square $=5.227$ with p-value.073 (Table 2). The frequency of AA, AG and GG genotypes (11.9. 27.5 and 60.6; respectively) among breast cancer females are shown in Table 3. Statistical difference was found between breast cancer $(n=97)$ and control $(n=53)$ among 
Table 1. Age Distribution and Body Mass Index among Breast Patients and Control

\begin{tabular}{lccc}
\hline variable & case & control & p-value \\
\hline age & & & \\
$40-50$ & 38 & 40 & 0.253 \\
$51-60$ & 48 & 46 & \\
$61-70$ & 59 & 57 & \\
$\quad$ more than 71 & 15 & 17 & \\
Mean \pm SD & $58.51 \pm 7.1$ & $55.3 \pm 5.3$ & \\
BMI $\left(\mathrm{kg} / \mathrm{m}^{2}\right)$ & & & \\
less than 25 & 47 & 93 & $<0.0001$ \\
$\quad$ more than 25 & 113 & 67 & \\
Mean \pm SD & $29.51 \pm 4.7$ & $99.98 \pm 3.8$ & $<0.001$ \\
\hline SD refers to standard deviation; P-value $<0.05$ was considered \\
statistically significant
\end{tabular}

Table 2. Hardy Weinberg Equilibrium Results for MspI Polymorphism and Its Respective Genotype in the Control Group

\begin{tabular}{lcccc}
\hline Genotype & Observed & Expected & $\mathrm{X}^{2}$ & p-value \\
\hline AA & 19 & 10.5 & 5.227 & 0.073 \\
AG & 44 & 60.96 & & \\
GG & 97 & 88.64 & & \\
\hline
\end{tabular}

Chi square $\left(\mathrm{X}^{2}\right)$ test was used. P-value $<0.05$ was considered statistically significant

GG (Arg/Arg) genotype $(\mathrm{OR}=2.986 ; 95 \% \mathrm{CI}=1.540$ to 5.787; $\mathrm{p}=0.001)$ compared to AA (Gln/Gln) genotype. While AG genotype did not show significant difference $(\mathrm{OR}=0.945 ; 95 \% \mathrm{CI}=0.478$ to 1.867$) ; \mathrm{p}$ - value $=0.869$.

The association between breast cancer type and genotype is shown in Table 4. No statistical significant between cancer type $(p=0.0723)$, cancer stage $(p=.0519)$ and any of the breast cancer genotypes (AA,AG,GG). Both estrogen receptor $(p=0.0003)$ and progesterone receptor $(\mathrm{p}=.023)$ were statistically associated with Q223R LEPR polymorphism (Table 4).

The results of this study showed that BMI among GG genotype showed statistically significant difference (P $<0.0001)$. While no statistical significant of BMI were associated with AA genotype $(\mathrm{p}=0.768)$ as shown in Table 5 .

GG genotype of Q223R LEPR polymorphism showed statistically significant increase in leptin level among obese patients $($ mean $\pm \mathrm{SD} ; 23.39 \pm 4.32)$ compared to control (17.83 \pm 5.67$)$; $\mathrm{p}$-value $=0.0001$ is shown in Table 6 . While no statistically significant differences were found at leptin level among obese patients with BMI more than 25 among AA and AG Q223R LEPR polymorphism
Table 3. Comparison of Genotypes Frequency, Odd ratio and 95\% confidence Interval between Breast Cancer Cases and Control

\begin{tabular}{lcccc}
\hline Genotype & $\begin{array}{c}\text { case } \\
(\%)\end{array}$ & $\begin{array}{c}\text { control } \\
(\%)\end{array}$ & OR $(95 \% \mathrm{CI})$ & p-value \\
\hline $\mathrm{AA}$ & $19(11.9)$ & $31(19.4)$ & Ref & 0.87 \\
$\mathrm{AG}$ & $44(27.5)$ & $76(47.5)$ & $0.945(0.478$ to 1.867$)$ & 0.001 \\
$\mathrm{GG}$ & $97(60.6)$ & $53(33.1)$ & $2.986(1.540$ to 5.789$)$ & \\
total & 160 & 160 & & \\
\hline AA is the reference & genotype; & p-value $<0.05$ was & considered \\
statistically significant & &
\end{tabular}

Table 4. The Relationship between Genotype Polymorphism and Pathological Features among Patients and Control

\begin{tabular}{lcccc}
\hline & AA & AG & GG & p-value \\
\hline Type of cancer & & & & \\
BC & 4 & 17 & 21 & 0.0723 \\
IDC & 7 & 11 & 43 & \\
DCIS & 1 & 9 & 14 & \\
LOS & 7 & 7 & 19 & \\
stage of cancer & & & & \\
I & 3 & 3 & 14 & 0.0519 \\
II & 3 & 9 & 39 & \\
III & 9 & 19 & 25 & \\
IV & 4 & 13 & 19 & \\
ER status & & & & \\
Positive & 14 & 39 & 53 & 0.0003 \\
Negative & 5 & 5 & 44 & \\
PR status & & & & \\
Positive & 13 & 41 & 73 & 0.023 \\
Negative & 6 & 3 & 24 & \\
\hline
\end{tabular}

ER, Estrogen Receptor; PR, Progesterone Receptor. P-value $<0.05$ is considered statistically significant

(p-value: 0.058 and .313 ; respectively)

\section{Discussion}

Obesity is associated with several illnesses including metabolic syndrome, diabetes, and cardiovascular disease and many cancers including breast cancer. The relationship between obesity and breast cancer is complex. Obesity increase morbidity among women with breast cancer but the exact mechanisms of these morbid relationships are still unclear. One linkage between breast cancer and obesity is serum leptin and leptin receptor polymorphism.

Several human LEPR gene SNPs have been identified (Chung et al., 1997). Among them, an A to G substitution

Table 5. The Relationship between Genotypes and BMI among Breast Cancer Patients and Control

\begin{tabular}{lcccccccc}
\hline Genotype & \multicolumn{3}{c}{ BMI less than 25 } & \multicolumn{3}{c}{ BMI more than 25 } \\
& case & control & OR $(95 \% \mathrm{CI})$ & p-value & case & control & OR (95\%CI) & p-value \\
\hline AA & 9 & 17 & ref & & 10 & 48 & ref & \\
AG & 38 & 18 & $0.251(0.094$ to 0.671$)$ & 0.058 & 6 & 34 & $1.181(0.392$ to 3.559) & \\
GG & 11 & 27 & $1.300(0.446$ to 3.787) & 0.631 & 86 & 36 & $0.087(0.040$ to .191) & \\
\hline
\end{tabular}

AA is the reference genotype. P-value $<0.05$ is considered statistically significant 
Table 6. Comparison of Leptin Levels among Obese and Non-Obese Breast Cancer Patients with Q223R LEPR polymorphism: AA, AG and GG by unpaired t-test

\begin{tabular}{lcccccc}
\hline Genotype & \multicolumn{2}{c}{$\begin{array}{c}\text { Mean leptin } \pm \mathrm{SD}(\mathrm{ng} / \mathrm{ml}) \\
\end{array}$} & with BMI less than 25(n) & \multicolumn{3}{c}{ Mean leptin $\pm \mathrm{SD}(\mathrm{ng} / \mathrm{ml})$ with BMI more than 25(n) } \\
& case & control & p-value & case & control & p-value \\
\hline AA & $15.39 \pm 3.04(7)$ & $12.19 \pm 4.14(17)$ & 0.079 & $20.89 \pm 4.92(12)$ & $18.11 \pm 4.34(48)$ & 0.058 \\
AG & $13.89 \pm 4.22(38)$ & $12.53 \pm 2.23(18)$ & 0.206 & $21.19 \pm 5.75(6)$ & $19.12 \pm 4.36(34)$ & 0.313 \\
GG & $14.17 \pm 3.74(11)$ & $12.11 \pm 3.04(27)$ & 0.085 & $23.39 \pm 4.32(86)$ & $17.83 \pm 5.67(36)$ & 0.0001 \\
\hline
\end{tabular}

AA is the reference genotype. P-value $<0.05$ is considered statistically significant; SD, standard deviation

at codon 223 (Q223R), that alters neutral amino acid to positively charged which may modifies signaling capacity, and associated with increased levels of serum leptin (Yiannakouris et al., 2001). Leptin-leptin receptor signaling modification linked with cell proliferation, metastasis, angiogenesis and chemo resistance which leads to cancer progression (Tsung-Chieh al., 2021). This study (Table 3) showed a significant difference in the frequency of GG between breast cancer females and control $(p=0.001)$. G allele correlated with a higher risk of breast cancer development (El-Hussina et al., 2018; Han et al., 2008). Also, this study showed that Q223R GG genotype is statistically more frequent among breast cancer patients $(60.6 \%)$ compared to healthy control (33.1\%). Similar results were reported among Egyptians (El-Hussiny et al., 2017) as well as among Chinese (Han et al., 2008). Moreover, it was shown that Q223R AA genotype associated with a lower risk of breast cancer (Mohammadzadeh et al., 2014). This study revealed that control healthy females significantly more frequent in Q223RAA genotype (19.4\%) compared to breast cancer patients $(11.9 \%)$.

An association between Q223R LEPR polymorphism and both estrogen $(\mathrm{p}=.0003)$ and progesterone receptor $(p=0.0232)$ among breast cancer females was shown in table 4. But, no association was found between breast cancer type and stage with Q223R LEPR polymorphism (Table 4). Resembling results were reported by Hołysz et al., (2021) who showed that and LEPR expression is more common among progesterone receptor positive breast cancer females. Contrary results were reported by Mohammadzadeh et al., (2014) who showed no significant association between Q223R polymorphism of LEPR gene and estrogen or progesterone receptor status. Estrogen modifies leptin receptor expression and can modulate leptin level Jenks et al., (2017). In vitro studies indicated the critical roles of leptin on estrogen receptor signaling proceeding breast cancer growth via inflammasome activation (Raut et al., 2019)

Breast cancer is the most commonly diagnosed cancer in women with obesity as a main risk factors, due to the proteins that is produced by adipose tissue which may initiate carcinogenesis, encourage tumor growth and metastasis. The association between Q223R LEPR polymorphism with obesity has been studied broadly. One study showed LEPR Q223R polymorphism was associated with BMI and waist circumference measures among overweight and obese subjects with the variant allele conferring a greater risk of adiposity (Illangasekera et al., 2020). Another study showed that LEPR Q223R polymorphisms and haplotype combination were associated with metabolic syndrome and obesity risk among Tunisians (Boumaizaet al., 2012; Nesrine et al., 2018). Recent study showed that single nucleotide polymorphisms (SNP) of leptin and its receptor with presence of oxidative stress produce a synergistic effect for obesity, that contribute to obesity generation with the environmental conditions of the individuals (DelgadilloGuzmán et al.,2020). Another report revealed that Q223R Polymorphism of the LEPR is a predictor of weight gain in childhood obesity (Marcos-Pasero et al., 2020).

Leptin as a cytokine is a protein that is produced by adipose tissue and described as a breast cancer growth factor. Serum leptin levels depend on the adipose tissue amount and LEP and LEPR genes expression (Lorincz et al., 2006). This study showed that GG genotype of Q223R LEPR polymorphism showed statistical significant increase in leptin level among obese patients (mean $\pm \mathrm{SD}$; $23.39 \pm 4.32)$ compared to control (14.17 \pm 3.74$)$; p-value $=.0001$ as shown in table 6 . Q223R LEPR polymorphism was associated with higher serum leptin levels and BMI among girls (Riestra et al., 2010). A Mexican study showed that the Q223R LEPR polymorphism was more prevalent among persons with higher levels of insulin, body fat and serum leptin levels (Guizar-Mendoza et al., 2005)

The result indicated that serum leptin levels significantly increased independently in BC cases for $\mathrm{BMI}>25$. Although the mechanism remains unclear, we speculated that the elevated levels of leptin were consistent with the amount of body fat in overweight/ obese groups, which could positively correlate with hyperleptinemia, insulin-sensitizing, and synthesis and activity of insulin-growth factor (IGF)-I and II. The IGF-I and II and leptin could have substantial effect on tumorigenesis through various intracellular pathways, which may synergize with other growth factors to enhance their mitogenic effects in obese hyperinsulinemic patients

\section{Author Contribution Statement}

M.A. formulated the original research idea, designed the study, and wrote the first draft. A. A contributed to the study design, collect data, performed experiments and statistical analysis

\section{Acknowledgements}

The authors are grateful to the Deanship of Scientific Research, The Hashemite University (grant No. $16 / 11 / 1501980$ ) for supporting the current work and for Hashemite University IRB committee for this research 
approval (IRB/16/11/1501980). We thank medical laboratory staff at the Hashemite University for their Support.

\section{Ethical approval}

Hashemite University IRB committee approval (IRB/16/11/1501980).

\section{Funding Sources}

The Hashemite University (grant No. 16/11/1501980) supported this study.

\section{Availability of data}

The data generated during the current study are available from the corresponding author on reasonable request.

\section{Conflict of Interest Statement}

The authors have no conflicts of interest to declare.

\section{References}

Amitabha R and Cleary MP (2017). The potential role of leptin in tumor invasion and metastasis. Cytokine Growth Factor Rev, 38, 80-97.

Angela M R-L, Jose Donato Jr (2017). The role of leptin in health and disease. Temperature (Austin), 4, 258-91.

Atoum M, Alzoughool F (2017). Vitamin D and Breast Cancer: Latest Evidence and Future Steps. Breast Cancer (Auckl), doi: $10.1177 / 1178223417749816$.

Atoum MF, Alzoughool F, Al-Hourani H (2020). Linkage between obesity leptin and breast cancer. Breast Cancer Basic Clin Res, https://doi.org/10.1177/1178223419898458

Boumaiza I, Omezzine A, Rejeb J, Rebhi L, Ouedrani A(2012). Relationship between leptin G2548A and leptin receptor Q223R gene polymorphisms and obesity and metabolic syndrome risk in Tunisian volunteers. Genet Test Mol Biomarkers, 16, 726-33.

Chooi YC, Ding, Cm Magkos, F (2019). The epidemiology of obesity. Metabolism, 92, 6-10.

Chung WK, Power-Kehoe L, Chua M, et al (1997). Exonic and intronic sequence variation in the human leptin receptor gene (LEPR). Diabetes, 46, 1509-11.

Delgadillo-Guzmán D, Sharara-Núñez AI, Pedroza-Escobar D, Castillo-Maldonado I, Quintanar-Escorza M (2020). Leptin G-2548A and Leptin Receptor Q223R gene polymorphisms are differently associated with oxidative process in Mexican mestizo and indigenous with obesity. Endocr Metab Immune Disord Drug Targets, doi: 10.2174/18715303206662010 09161630.

Ehmsen S, Ditzel HJ (2020). Signaling pathways essential for triple-negative breast cancer stem-like cells. Stem Cells, 39, 133-43.

El-Hussiny M, Atwa M, Rashad W, Shaheen D, Elkady N (2017). Leptin receptor Q223R polymorphism in Egyptian female patients with breast cancer. Wspolczesna Onkol, 21, 42-7.

Ellulu MS, Patimah I, Khaza'ai H, Rahmat A, Abed Y (2017). Obesity and inflammation: The linking mechanism and the complications. Arch Med Sci, 13, 851-63.

Gholamalizadeh M, Doaei S, Moghadam A, et al (2019). Metaanalysis of Studies Investigating Association between FTO Gene Polymorphisms and Breast Cancer. Asian Pac J Cancer Biol, 4, 75-9

Gregor MF, Hotamisligil GS (2011) inflammatory mechanisms in obesity. Annu Rev Immunol, 29, 415-45.
Guízar-Mendoza JM, Amador-Licona N, Flores-Martínez SE, et al (2005) Association analysis of the Gln223Arg polymorphism in the human leptin receptor gene, and traits related to obesity in Mexican adolescents. J Hum Hypertens, 19, 341-6.

Han CZ, Du LL, Jing JX, et al (2008). Associations among lipids, leptin, and leptin receptor gene gin223arg polymorphisms and breast cancer in China. Biol Trace Elem Res, 126, 38-48.

Hernández-Caballero ME, Sierra-Ramírez JA(2015). Molecular Biology Single nucleotide polymorphisms of the FTO gene and cancer risk: an overview Reports. Mol Biol Rep, 42, 699-704.

Hołysz H, Paszel-Jaworska A, Romaniuk-Drapała A, GrodeckaGazdecka S, Rubiś B (2021). LEP (-2548G>A LEP) and LEPR (223Gln $>$ Arg, 109Lys $>$ Arg) polymorphisms as breast cancer risk factors in the Polish female population. Mol Biol Rep, 48, 3237-44

Illangasekera YA, Kumarasiri PVR, Fernando DJ, Dalton CF (2020). Association of the leptin receptor Q223R (rs1137101) polymorphism with obesity measures in Sri Lankans. BMC Res Notes, 13, 34.

Jenks MZ, Fairfield HE, Johnson EC, Morrison RF, Muday GK (2017). Sex steroid hormones regulate leptin transcript accumulation and protein secretion in 3T3-L1 cells. Sci Rep, 7, 8232.

Kabat GC, Kim MY, Lee JS, et al (2017). Metabolic obesity phenotypes and risk of breast cancer in postmenopausal women. Cancer Epidemiol Biomarkers Prev, 26, 1730-5.

Lorincz AM, Sukumar S (2006). Molecular links between obesity and breast cancer. Endocr Relat Cancer, 13, 279-92.

Marcos-Pasero H, Aguilar-Aguilar E, Colmenarejo G, et al (2020). The Q223R polymorphism of the leptin receptor gene as a predictor of weight gain in childhood obesity and the identification of possible factors involved. Genes (Basel), 11, 560.

Mohammadzadeh G, Ghaffari MA, Bafandeh A, Hosseini SM (2014). Effect of leptin receptor Q223R polymorphism on breast cancer risk. Iran J Basic Med Sci, 17, 588-94.

Nesrine Z, Haithem H, Imen B, et al (2018). Leptin and Leptin receptor polymorphisms, plasma Leptin levels and obesity in Tunisian volunteers. Int $J$ Exp Pathol, 99, 121-30.

Pérez-Montarelo D, Fernández A, Barragán C, et al (2013). Transcriptional characterization of porcine leptin and leptin receptor genes. PLoS One, $\mathbf{8}$, e66398.

Raut PK, Kim SH, Choi DY, Jeong GS, Park PH (2019). Growth of breast cancer cells by leptin is mediated via activation of the inflammasome: Critical roles of estrogen receptor signaling and reactive oxygen species production. Biochem Pharmacol, 161, 73-88.

Riestra P, García-Anguita A, Schoppen S, et al ( 2010). Sexspecific association between leptin receptor polymorphisms and leptin levels and BMI in healthy adolescents. Acta Paediatr, 99, 1527-30.

Singletary SE, Allred C, Ashley P, et al (2020). Revision of the American joint committee on cancer staging system for breast cancer. J Clin Oncol, 20, 3628-36.

Tsung-Chieh L, Hsiao M (2021). Leptin and Cancer: Updated Functional Roles in Carcinogenesis, Therapeutic Niches, and Developments. Int J Mol Sci, 22, 2870.

Whitlock G, Lewington S, Sherliker P, et al (2009). Prospective Studies Collaboration. Body-mass index and cause-specific mortality in 900,000 adults: collaborative analyses of 57 prospective studies. Lancet, 373, 1083-96.

Yiannakouris N, Yannakoulia M, Melistas L, et al (2001). The Q223R polymorphism of the leptin receptor gene is significantly associated with obesity and predicts a small percentage of body weight and body composition variability. 
Manar F Atoum and Ala'a Abdel Hamaid Alparrey

$J$ Clin Endocrinol Metab, 86, 4434-9.

Zabeau L, Peelman F, Tavernier J (2014). Antagonizing leptin: current status and future directions. Biol Chem, 395, 499514.

\section{(ब) $(1)$}

This work is licensed under a Creative Commons AttributionNon Commercial 4.0 International License. 